\title{
Raltitrexed + irinotecan as second-line chemotherapy in elderly patients with advanced colorectal cancer
}

\author{
Barbara Vandendriessche $^{1^{*}}$, Filip Geurs ${ }^{2^{*}}$, Ingeborg Hilderson ${ }^{3^{*}}$ \\ ${ }^{1}$ Regionaal Ziekenhuis SINT MARIA, Halle, Belgium; ${ }^{*}$ Corresponding Author: g@,regzhsintmaria.be \\ ${ }^{2}$ ZH Sint Maria, Brussel, Belgium; "Corresponding Author: f.geurs@regzhsintmaria.be \\ ${ }^{3}$ Medical Oncology Department, REG ZH Sint Maria, Halle, Belgium; ${ }^{*}$ Corresponding Author: ingeborg.hilderson@ugent.be
}

Received 7 August 2012; revised 14 September 2012; accepted 8 October 2012

\section{ABSTRACT}

Aims and Background: Irinotecan is a standard option for relapsed/refractory advanced colorectal cancer. Combination with raltitrexed and irinotecan at lower than MTD doses should preserve disease stabilisation while decreasing toxicity. Patients and Methods: From January 2004 to April 2009, we analyzed, retrospectively, our data on irinotecan + raltitrexed, fixed doses, as a second-line chemotherapy in elderly patients (>70 years) with advanced colorectal cancer after failure of oxaliplatin based chemotherapy twenty-three patients were evaluated. Irinotecan $350 \mathrm{mg}+$ raltitrexed $2.6 \mathrm{mg}$ were given every 3 weeks. Tumo $r$ measurements were obtained after every third course of therapy. Toxicity was assessed weekly using the National Cancer Institute Common Toxicity Criteria, version 2. Results: The median number of treatment courses received per patient was 4 (range, 1 - 8). All patients were assessable for toxicity and 21 for response. The most frequently observed severetoxicities were diarrhea (grade 2, 13\%) No cases of significant neutropenia occurred. Objective partial responses were observed in 3 patients (13\%). An additional 10 patients $(43 \%)$ had stable disease as their best response. To date, 12 patients have progressed with a median timeto-progression of 4.3 months and a median survival of 8.3 months. Conclusions: A three weekly irinotecan + raltitrexed administration can induce tumor control in elderly patients with advanced colorectalcancer that has progressed during or shortly after oxaliplatin-based chemotherapy. The diarrhea by irinotecan, seems mitigated by coadministration of a smaller dose of raltitrexed

Keywords: Colorectal; Elderly; Irinotecan;

Second-Line; Unresectable

\section{INTRODUCTION}

Irinotecan (CPT-11), a DNA topoisomerase I inhibitor, has demonstrated antitumor activity as a single agent in the second-line treatment of advanced colorectal cancer (ACC) $[1,2]$. In Europe, the drug was developed as a 3 -weekly regimen $\left(350 \mathrm{mg} / \mathrm{m}^{2}\right.$ every 3 weeks), whereas in the USA, a weekly regimen $\left(100-125 \mathrm{mg} / \mathrm{m}^{2} /\right.$ week for 4 consecutive weeks out of 6 ) wasevaluated 3 - 5. In patients with 5-fluorouracil (5-FU)-refractory disease, these phase II trials demonstrated objective response rates of $12 \%$ to $15 \%$ and median survivals of 8 to 9 months. However, the major toxicities encountered with these regimens were grade 3 for diarrhea, neutropenia, nausea and vomiting, and alopecia. Several randomized studies have studied the optimal regimen for single-agent CPT-11. In the first study, CPT-11 was administered weekly $\left(125 \mathrm{mg} / \mathrm{m}^{2}\right)$, once every 2 weeks $\left(250 \mathrm{mg} / \mathrm{m}^{2}\right)$ or once every 3 weeks $\left(350 \mathrm{mg} / \mathrm{m}^{2}\right)$, or as a continuous infusion $\left(10 \mathrm{mg} / \mathrm{m}^{2} /\right.$ day, 14-day continuous infusion every 3 weeks). It was concluded that the 3 -week and 2-week regimens showed better tolerance and induced higher response rates than the weekly regimen 6 . In another study, CPT-11 schedules of weekly $\left(125 \mathrm{mg} / \mathrm{m}^{2}\right)$ and of once every 3 weeks $\left(350 \mathrm{mg} / \mathrm{m}^{2}\right)$ demonstrated similar efficacy and quality of life. However, the 3-week regimen was associated with a significantly lower incidence of severe diarrhea 7 . By adding raltitrexed to 3 weekly irinotecan, diarrhea and neutropenia were decreased. By lowering the dose to the lowest one active for both drugs, we hoped to avoid the neutropenia associated with three weekly irinotecan, whilst maintaining an easy outpatient regimen conceived for elderly patients risk. Due to the physiological reduction of functional organ reserve and the presence of comorbid conditions, elderly patients are often excluded from clinical trials. These subjects frequently suffer from tumor-related symptoms and need some kind of palliative treatment. In clinical practice, they often receive inadequate and untested treatments [9, 10]. The aforementioned trials did not obtain exhaustive 
information on the CPT-11 activity and tolerability in this subset of patients. From January 2004 to April 2011, we retrospectively collected our data on elderly patients with ACC responding to defined selection criteria and treated with irinotecan + raltitexed as second-line treatment following 5-FU/oxaliplatin-based therapy.

\section{PATIENTS AND METHODS}

\subsection{Patient Selection}

Patients with the following inclusion criteria were considered for retrospective analysis: histologically confirmed ACC; age 70 years; performance status PS) 2 (Eastern Cooperative Oncology Group); at least one bidimensionally measurable lesion; disease progression during or within 6 months of 5-FU/oxaliplatin-based chemotherapy for advanced disease; radiotherapy acceptable if it was completed 3 weeks before the start of CPT-11 chemotherapy and not including the only site of measure able disease; adequate hematologic reserve and hepatic and renal function, documented by WBC $3000 \mathrm{~mm}^{3}$, absolute neutrophil count $1500 \mathrm{~mm}^{3}$, hemoglobin level 9.0 $\mathrm{g} / \mathrm{dL}$, platelets $100,000 \mathrm{~mm}^{3}$, serum bilirubin $1.5 \mathrm{mg} / \mathrm{dL}$, AST (SGOT) 3x and 5x upper level of institutional normal if liver metastases were present), and serum creatinine $2.0 \mathrm{mg} / \mathrm{dL}$. Patients with metastatic involvement of the CNS, a psychiatric disorder that could interfere with treatment compliance, significant concurrent infection or concurrent or previous malignancy, or significant cardiac disease were excluded.

\subsection{Staging, Response and Toxicity Evaluation}

Retrospectively analyzed patients were assessed according to usual clinical practice including a complete medical history and a general physical examination. Tumor staging was assessed by a two-view chest X-ray, upper abdomen ultrasound and, when appropriate, diagnostic scans (i.e., computed tomography, magnetic resonance imaging, or bone scan). Complete blood cell counts with platelet and differential counts were obtained weekly during chemotherapy. Serum chemistries were repeated at least once every course. Physical examination, tumour marker levels (CEA and Ca 19.9) and radiologic tumour parameter assessment were obtained every $3 \mathrm{cy}-$ cles of treatment. The World Health Organization (WHO) criteria were used for the definition of response, response duration, time to progression (TTP), and survival1. 1) Decreased tumour marker levels were considered useful for monitoring therapy in patients whose CEA and CA 19-9 had been elevated at baseline, but were not used to evaluate the response. All adverse reactions were recorded before each chemotherapy course. Toxicities were scored according to the standard National Cancer Institute common toxicity criteria, version. 2) The worst experienced grade was recorded for each patient and type of toxicity.

\subsection{Statistical Methods}

Duration of response was calculated from the first documentation of response to disease progression or last examination. TTP was determined by the interval from the beginning of therapy to the date when disease progression was first documented. Survival was measured from the date of registration to the date of death. Patients dying before completion of restaging were defined as "progressed" on the date of death.

Overall survival from the date of the beginning of 5FU/oxaliplatin-based first-line chemotherapy was also calculated.

\section{TREATMENT}

The analysis was conducted in one centre. Patients received irinotecan $350 \mathrm{mg}(1 \mathrm{~h}$ infusion $)+$ raltitrexed 2.5 $\mathrm{mg}$ (15 min infusion ) on days 1 repeated every 3 weeks. Corticosteroids and granisetrons were delivered before each chemotherapy infusion to prevent emesis. Primary prophylaxis with Granulocyte Colony-Stimulating Factor (GCSF) was not allowed. On days 1 the minimum requirements for chemotherapy administration were a neutrophil count of $1500 \mathrm{~mm}^{3}$, a platelet count of 100,000 $\mathrm{mm}^{3}$, a hemoglobin level $9.0 \mathrm{~g} / \mathrm{dL}$, and no sign of organ toxicity (excluding alopecia).

For the patients who experienced hemoglobin levels $<10 \mathrm{~g} / \mathrm{dL}$, the recombinant human erythropoietin was admitted. Loperamide, $2 \mathrm{mg}$ orally every $2 \mathrm{hr}$, was recommended in the event of delayed diarrhoea and discontinued $12 \mathrm{~h}$ after the last liquid stool. If diarrhoea was not under control after $48 \mathrm{hr}$, other supportive measures, including hospitalization for iv rehydration, were prescribed. In case of appearance of grade 3 - 4 diarrhoea, a $20 \%$ dose reduction was chosen for the subsequent courses. Treatment was administered until evidence of disease progression, unacceptable toxicity or patient refusal.

\section{RESULTS}

\subsection{Patient Demographics}

Twenty-three patients treated in the involved institution were analyzed. Their characteristics are shown in Table 1. The median age of patients was 75 years (range, 70 - 89), and 10 patients (43\%) were 75 years old or older. Patients generally had widespread disease, with the most frequent distant sites including liver, lung, and peritoneum. Six patients $(26 \%)$ had received prior radiotherapy. 
Table 1. Main characteristics of the study patients.

\begin{tabular}{|c|c|}
\hline Characteristics & All patients (\%) \\
\hline No. of patients & $23(100)$ \\
\hline \multicolumn{2}{|l|}{ Gender } \\
\hline Male & $11(48)$ \\
\hline Female & $12(52)$ \\
\hline \multicolumn{2}{|l|}{ Age (yr) } \\
\hline Median & 75 \\
\hline Range & $70-79$ \\
\hline \multicolumn{2}{|l|}{ Primary site } \\
\hline Colon & $15(65)$ \\
\hline Rectum & $8(35)$ \\
\hline \multicolumn{2}{|l|}{ Site of metastases } \\
\hline Liver & $15(65)$ \\
\hline Local (recurrent) & $5(22)$ \\
\hline Lung & $5(22)$ \\
\hline Peritoneum & $4(17)$ \\
\hline Lymph nodes & $2(9)$ \\
\hline Bone & $2(9)$ \\
\hline \multicolumn{2}{|l|}{ Involved sites } \\
\hline 1 & $14(61)$ \\
\hline 2 & $7(30)$ \\
\hline$>2$ & $2(9)$ \\
\hline \multicolumn{2}{|l|}{ ECOG performance status } \\
\hline 0 & $11(48)$ \\
\hline 1 & $12(52)$ \\
\hline \multicolumn{2}{|l|}{ Previous therapy } \\
\hline Surgery & $23(100)$ \\
\hline First-line chemotherapy & $23(100)$ \\
\hline Radiotherapy & $4(17)$ \\
\hline
\end{tabular}

\subsection{Treatment Duration}

A total of 114 cycles of treatment were administered, with a median of 4 cycles per patient (range, $1-8$ ). Four patients $(17.3 \%)$ received less than three cycles because of disease progression, 2 patients $(8.6 \%)$ received less than three cycles because of adverse events.

Nevertheless, all of the patients evaluated were considered assessable for efficacy and toxicity. There were no cases of significant delay or dose reduction due to neutropenia.
The median relative dose intensity value was $95 \%$.

\subsection{Tumor Response and Survival}

In our analysis, the overall response rate was $13 \%$.The median duration of response was 4.1 months (range, 3 $7+)$. In addition, 10 patients (43.4\%) maintained stable disease, and another 10 patients (43.4\%) had disease progression. The median follow-up for alive patients was 10.4 months. At the time of analysis, the median TTP was 4.3 months (range, $1-8+$ ) and the median survival was 8.3 months (range, $1-16+$ ). Excluding those patients not truly assessable, the response rate reached was $14.2 \%$. The overall median survival from the beginning of the first-line chemotherapy exceeded 18 months.

\section{SAFETY}

The main severe hematologic toxicity was neutropenia, which was grade 3 in $30.4 \%$ and no grade 4 toxicity. Diarrhoea was the main non-hematologic toxicity, but grade 2 diarrhoea occurred in $13 \%$ of patients. One patient reported severe diarrhoea not responsive to rescue Anemia, fatigue, and alopecia were frequent toxicities.

Table 2. Results.

\begin{tabular}{|c|c|}
\hline & Total no. (\%) \\
\hline Patients entered & $23(100)$ \\
\hline Patients assessable & $21(97)$ \\
\hline \multicolumn{2}{|l|}{ Response } \\
\hline $\mathrm{CR}$ & $-(0)$ \\
\hline PR & $3(13)$ \\
\hline $\mathrm{SD}$ & $10(43.4)$ \\
\hline PD & $10(43.4)$ \\
\hline Response rate & 13.0 \\
\hline \multicolumn{2}{|c|}{ Median duration, months } \\
\hline Response rate & 4.1 \\
\hline Range & $3-7+$ \\
\hline ТTP & 4.3 \\
\hline Range & $1-8+$ \\
\hline Survival, months & 8.3 \\
\hline Range & $1-16+$ \\
\hline
\end{tabular}

$\mathrm{CR}$, complete response; $\mathrm{PR}$, partial response; $\mathrm{SD}$, stable disease; $\mathrm{PD}$, progression of disease; TTP, time to progression. 
Table 3. Different authors on second line irinotecan (or combinations) after oxaliplatin.

\begin{tabular}{|c|c|c|c|c|c|c|c|}
\hline author & year & $1 \mathrm{st}$ & 2 nd & number & $\mathrm{RR}$ & PFS (months) & reference \\
\hline Tournigand & 1999 & folfox & folfiri & 34 & 6 & 4 & 21 \\
\hline Maindrault & 2000 & folfox & folfiri & 22 & 20 & not & 24 \\
\hline Louvet & 2007 & folfox & pem/iri & 44 & 14 & not & 23 \\
\hline Sorbye & 2007 & folfox & folfiri & 59 & 7 & 4.1 & 25 \\
\hline Recchia & 2004 & folfox & folfiri & 35 & 20 & 7.1 & 27 \\
\hline Marbro & 2004 & folfox & Folfiri-3 & 65 & 17 & 4.1 & 26 \\
\hline our series & 2009 & xelox & Tom-iri & 23 & 13 & 4.2 & \\
\hline
\end{tabular}

No thromboembolic phenomena occurred. No treatment high-dose loperamide administration. This required hospital admission related death was reported. The incidence of any cholinergic symptom was significantly low (2 patients, $8.6 \%$ ).

\section{DISCUSSION}

The treatment of elderly patients is an emerging issue. Although irinotecan monotherapy is recognized as the treatment of choice in second-line therapy (after failure of 5-FU) in ACC, unfortunately only a few studies have evaluated its feasibility in elderly patients. Most of the trials enrolled patients with a cut-off age ranging from 60 - 65 years, probably not representative of a real elderly population. Nevertheless, a higher rate of adverse events was detected in a CPT-11 study in patients 65 years compared with patients younger than 65 years (rate of grade 3 and 4 diarrhoea, 39\% and 19\%, respectively) [5], although this has not been confirmed in other studies $[12,13]$. The dose-limiting toxicities for CPT-11 are delayed diarrhea and neutropenia $[14,15]$. However, toxicity patterns depend on the CPT-11 schedule. Grade 3 - 4 diarrhea occurred in $36 \%$ of the patients treated on a weekly basis and in $19 \%$ of those treated once every 3 weeks $(\mathrm{P}=0.002)$ in the trial of Fuchs et al. [7], providing comparative data on the efficacy, tolerability, and effect on quality of life between the schedules. A higher treatment-related mortality rate was noted among patients receiving weekly CPT-11 (5.3\%) than among those given the every-3-weeks schedule $(1.6 \%)$, although this difference was not statistically significant. In the weekly group, at least three of five treatment-related deaths were caused by diarrhoea and dehydration. In contrast, grade 3 - 4 neutropenia appeared slightly more frequent in the every 3 weeks schedule ( $34 \%$ vs $29 \%$ ), but this difference was not statistically significant. On the other hand, the randomized phase II study of Schoe maker et al. [6] reporting severe neutropenia in $34 \%$ of the patients treated once every 3 weeks and in $25 \%$ of those treated weekly, also supports the idea that these differences in toxicity profile are probably related to the administration schedule rather than the dose per cycle. Adding raltitrexed to three weekly irinotecan proved to decrease diarrhoea. In our study, we used lower doses of both drugs, while maintaining its efficacy; in comparison to other second line regimens.

The objective response rate $(13 \%)$ is consistent with those reported in the analysis of pooled data from 455 patients from European studies and 304 patients from American studies $[4,18,19]$. The median TTP of 4.3 months and the median survival of 8.3 months are similar to those of the aforementioned pooled data analysis (Table 3). Interestingly, we observed that the overall median survival from the beginning of the first chemtherapy exceeded 18 months. These data prompted us to use a second-line chemotherapy in the elderly after firstline failure. This finding suggests that it is important to make all drugs that have well-demonstrated clinical activity in ACC available to all patients to guarantee maximal benefit of systemic therapy for survival, as mentioned in the analysis of Grothey et al. [19]. Actually, this schedule should be prospectively used as a skeleton of active and lower dose of chemotherapy to which targeted treatments should be added.

The advent of several biologic agents such as cetuximab and bevacizumab, which demonstrated to be beneficial and tolerable without adding supplementary toxicity has revolutionazed the management of metastatic colon cancer. Determining a chemotherapeutic basis to whom these drug can be added will become a major issue, especially in elderly patients. However, it is important to bear in mind that our patients were a subpopulation of elderly patients characterized by a good general condition. Therefore, these data cannot be extrapolated to the 
elderly population in general, but must be confirmed by randomized prospective studies.

\section{REFERENCES}

[1] Cunningham, D., Pyrhönen, S., James, R.D., Punt, C.J.A., Hickish, T.F., Heikkila, R., Johannesenm, T.B., Starkhammar, H., Thopam, C.A., Awad, L., Jacques, C. and Herait, P. (1998) Randomised trial of irinotecan plus supportive care versus supportive care alone after fluorouracil failure for patients with metastatic colorectal cancer. Lancet, 352, 1413-1418.

[2] Rougier, P, Van Cutsem, E., Bajetta, E., Niederle, N., Possinger, K., Labianca, R., Navarro, M., Morant, R., Bleiberg, H., Wils, J., Awad, L., Herait, P. and Jacques, C. (1998) Randomised trial of irinotecan versus fluorouracil by continuous infusion after fluorouracil failure in patients with metastatic colorectal cancer. Lancet, 352, 1407-1412.

[3] Armand, J.P., Ducreux, M., Mahjoubi, M., Abigerges, D., Bugat, R., Chabot, G., Herait, P., De Forni, M. and Rougier, P. (1995) CPT-11 (irinotecan) in the treatment of colorectal cancer. European Journal of Cancer, 31A, 1283-1287.

[4] Pitot, H.C., Wender, D.B., O’Connell, M.J., Schroeder, G., Goldberg, R.M., Rubin, J., Mailliard, J.A., Knost, J.A., Ghosh, C., Kirschling, R.J., Levitt, R. and Windschitl, H.E. (1997) Phase II trial ofirinotecan in patients with metastatic colorectal carcinoma. Journal of Clinical Oncology, 15, 2910-2919.

[5] Rothenberg, M.L., Cox, J.V., De Vore, R.F., Hainsworth, J.D., Pazdur, R., Rivkin, S.E., Macdonald, J.S., Geyer, C.E., Sandbach, J., Wolf, D.L., Mohrland, J.S., Elfring, G.L., Miller, L.L. and Von Hoff, D.D. (1999) A multicenter, phase II trial of weekly irinotecan (CPT-11) inpatients with previously treated colorectal carcinoma. Cancer, $\mathbf{8 5}$, 786-795.

[6] Schoemaker, N.E., Kuppens, I.E.L.M., Moiseyenko, V., Glimelius, B., Kjaer, M., Starkhammer, H., Richel, D.J., Smaaland, R., Bertelsen, K., Poulsen, J.P., Voznyi, E., Norum, J., Fennelly, D., Tveit, K.M., Garin, A., Gruia, G., Mourier, A., Sibaud, D., Lefebvre, P., Beijnen, J.H., Schellens, J.H. and Bokkel-Huinink, W.W. (2004) A randomisedphase II multicentre trial of irinotecan (CPT-11) using four different schedules in patients with metastatic colorectalcancer. British Journal of Cancer, 91, 14341441.

[7] Fuchs, C.S., Moore, M.R., Harker, G., Villa, L., Rinaldi, D. and Hecht, J.R. (2003) Phase III comparison of two irinotecan dosing regimensin second-line therapy of metastatic colorectal cancer. Journal of Clinical Oncology, 21, 807-814.

[8] Hwang, J.J., Eisenberg, S.G. and Marshall, J.L. (2003) Improving the toxicity of irinotecan/5-FU/leucovorin: A 21-day schedule. Oncology, 17, 37-43.

[9] Fentiman, I.S., Tirelli, U., Monfardini, S., Schneider, M., Festen, J., Cognetti, F. and Aapro, M.S. (1990) Cancer in the elderly: why so badly treated. Lancet, 28, 1020-1022.
[10] Monfardini, S. and Yancik, R. (1993) Cancer in the elderly: Meeting the challenge of an aging population. Journal of the National Cancer Institute, 85, 532-538.

[11] Miller, A.B., Hoogstraten, B., Staquet, M. and Winkler, A. (1981) Reporting results of cancer treatment. Cancer, 47, 207-214.

[12] Rougier, P., Mitry, E., Cunningham, D., Roth, A., Clavero-Fabri, M.C., Magherini, E., Mery-Mignard, D., Awad, L. and Douillard, J.Y. (2003) Is age a prognostic factor of toxicity and efficacy in patients(pts) with metastatic colorectal cancer (MCRC) receiving irinotecan in combination with 5FU/folinic acid (FA). American Society of Clinical Oncology, 22.

[13] Chau, I., Norman, A.R., Cunningham, D., Waters, J.S., Topham, C., Middleton, G., Hill, M., Ross, P.J., Katopodis, R., Stewart, G. and Oates, J.R. (2004) Elderly patients with fluoropyrimidine andthymidylate synthase inhibitorresistant advanced colorectal cancer derive similar benefit without excessive toxicity when treated with irinotecan monotherapy. British Journal of Cancer, 91, 1453-1458.

[14] Rothenberg, M.L., Kuhn, J.G., Burris, H.A., Nelson, J., Eckardt, J.R., Tristan-Morales, M., Hilsenbeck, S.G., Weiss, G.R., Smith, L.S. and Rodriguez, G.I. (1993) Phase I and pharmacokinetic trial of weekly CPT-11. Journal of Clinical Oncology, 11, 2194-2204.

[15] Abigerges, D., Chabot, G.G., Armand, J.P., Herait, P., Gouyette, A. and Gandia, D. (1995) Phase I and pharmacologic studies of the camptothecin analog irinotecan administered every 3 weeks in cancer patients. Journal of Clinical Oncology, 13, 210-221.

[16] Benavides, M., Garcia-Alfonso, P., Cobo, M., MunozMartin, A., Gil-Calle, S., Carabantes, F., Villar, E., Graupera, J., Balcells, M. and Perez-Manga, G. (2004) Weekly irinotecan (CPT-11) in 5-FU heavily pretreated and poor-performance-status patients with advanced colorectal cancer. Medical Oncology, 21, 255-262.

[17] Karaoglu, A., Yalcin, S., Tekuzman, G., Kars, A., Celik, I., Guler, N., Ozisik, Y., Turker, A., Barista, I. and Gullu, I. (2003) Weekly irinotecan in patients with metastatic colorectal cancer failing 5-fluorouracil-based chemotherapy: Efficacy and prognostic factors. Tumori, 89, 141-145.

[18] Rougier, P. and Mitry, E. (2000) Colorectal cancer chemotherapy: Irinotecan. Seminars in Oncology, 27, 138143.

[19] Grothey, A., Sargent, D., Goldberg, R.M. and Schmoll, H.J. (2004) Survival of patients with advanced colorectal cancer improves with the availability of fluorouracilleucovorin, irinotecan, and oxaliplatin in the course of treatment. Journal of Clinical Oncology, 22, 1209-1214.

[20] Rosati, G. and Cordio, S. (2006) Single agent irinotecan as second line weekly chemotherapy in elderly patients with advanced colorectal cancer. Tumori, 92,290-294.

[21] Tournigand, C., André, T., Achille, E., Lledo, G., Flesh, M., Mery-Mignard, D., et al. (2004) Folfiri followed by FOLFOX6 or the reverse sequence in advanced colorectal cancer: A randomized GERCOR study. Journal of Clinical Oncology, 22, 229-237.

[22] Louvet, C., André, T., Gamelin, E., Hebbar, M., Mabro, 
M., Bennamoun, M., Rassam, H. and De Gramont. (2010) Phase II study of biweekly pemetrexed plus irinotecan as second-line therapy for metastatic colorectal cancer. American Journal of Clinical Oncology.

[23] Mabro, M., Artru, P., André, T., Flesch, M., MaindraultGoebel, F., Landi, B., Lledo, G., Plantade, A., Louvet, C. and De Gramont, A. (2006) A phase II study of FOLFIRI-3 (double infusion of irinotecan combined with LV5FU) after FOLFOX in advanced colorectal cancer patients. British Journal of Cancer, 94, 1287-1292.

[24] Sorbye, H., Berglund, A., MagneTveits, K., Ogreid, D., Hoff Wandere, E., et al. (2007) Secondary treatment and predictive factors for second-line chemotherapy after first-line oxaliplatin-based therapy in metastatic colorec- tal cancer. Acta Oncologica, 46, 982-988.

[25] Mabro, M., Artru, P., Andre, T., Flesch, M., MaindraultGoebel, F., Landi, B., Lledo, G., Plantade, A., Louvet, C. and Gramont, A. (2006) A phase II study of FOLFIRI-3 (double infusion of irinotecan combined with LV5FU) after FOLFOX in advanced colorectal cancer patients. British Journal of Cancer, 94, 1287-1292.

[26] Recchia, F., Nuzzo, A., Lalli, A., Di Lullo, L., De Filippis, S., Saggio, G., Di Blasio, A. and Rea, S. (2003) Multicenter phase II study of CPT-11 fractionated over two days with bimonthly leucovorin and 5-fluorouracil in patients with metastatic colorectal cancer. Anti-Cancer Research, 23, 2903-2908. 